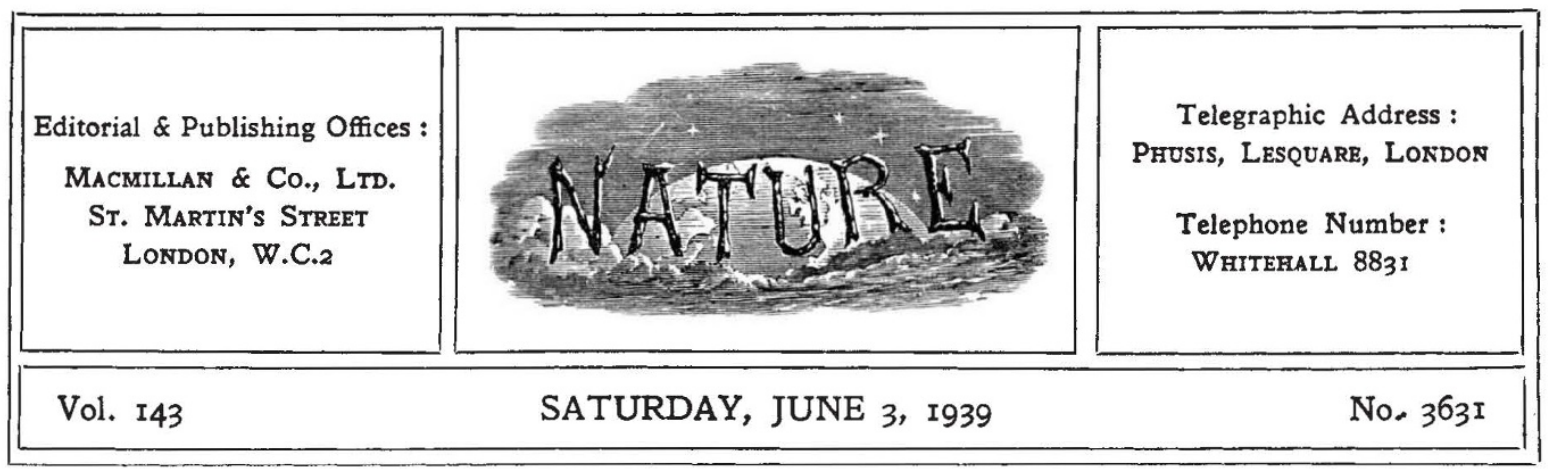

\title{
Whither the Gas Industry?
}

$\mathrm{T}$ HE "independent non-party group" concerning itself with "Political and Economic Planning" under the suggestively abbreviated title P E P, has added to its publications a "Report on the Gas Industry in Great Britain"*. This report has been produced by the Gas Group of PE P and will be followed, we are told, by a more comprehensive P E P report on fuel policy in Great Britain, for the purposes of which the findings of the coal, gas and electricity groups will be re-examined. The work has been well done and presents a picture of the gas industry as it exists to-day of a kind that, for interesting and revealing detail, has no rival. The development of the industry through various phases is also indicated with clarity, which is very desirable for a full understanding of the present situation and future possibilities.

For a long period after Murdoch and Winsor came forward a century ago with their processes for making coal-gas and using its luminous flame for lighting, improving technique simply served that purpose, important but limited, and under conditions of virtual monopoly. The introduction of the Bunsen burner and the Welsbach mantle, and the development of electrical supply, then played their part in gradually broadening the basis of the gas industry as a purveyor of heat as well as light, and in creating its competitive aspect. This has brought about the condition of to-day, in which the gas industry is no longer one for the heating of coal in retorts for making lighting-gas, but one for the systematic treatment of coal by carbonization and gasification in such a manner as to secure thereby products of

* Report on the Gas Industry in Great Britain: a Survey of the Current Trends and Problems of the Industry, with Proposals for its Future Development. Pp. vii +213. (London: P E P, 1939.) 108.6d.net. maximum thermal, chemical and monetary values. The realization of these values has also demanded agencies for their proper utilization and, brought into the scope of the industry, schemes for the distribution of gas (the primary product) and the provision of efficient appliances for its combustion, as well as a new-found solicitude for the yields, quality and fate of coke, tar, and such chemical products as benzole, with its practically unlimited market as a liquid fuel.

With this increasing complication there has arisen the paramount necessity for scientific and efficient management, and for wise and far-seeing administration, if the industry is to deal adequately with the problems it has to face. There are such matters to settle as the degree of linking-up in production and management which may with advantage be effected, partly with a view to better supply and partly so as to bring first-class men into more effective use than is possible with the very numerous scattered works now in being and working independently. It may be pointed out that the small gas-works is not at all necessarily an uneconomical unit if well designed, constructed and run. Similarly, the best method of utilizing the spare gas from coke-oven plants well repays careful study. The possibilities in that direction have been demonstrated already in such districts as Sheffield, where the cheap supply obtainable by the gas company from neighbouring coke-oven plants has been largely responsible for the wide and extending use of coal-gas in metallurgical and other industrial furnaces.

Such utilization of coke-oven gas seems an obvious and desirable economy; but it raises questions which require careful consideration when one remembers, for example, that the coke oven 
cannot with advantage continue to make unwanted metallurgical coke in order that the gas supply may be maintained. There is, again, the vexed question of tariffs in the gas industry, the allotment of charges on a rational basis to small and large consumers, where the gas industry has inherited statutory limitations imposed in the old days, which tell against it in competition with the newer electrical undertakings, the successful working of which is indeed largely conditioned by their greater freedom in this respect.

The discussion of these matters, even in brief, is not possible here; but they are gone into thoroughly in the P E P report, which is, in effect, a call to the industry to organize itself in a manner befitting its responsibilities and opportunities. The acknowledgment is rightly made of much that has already been done. It has to be admitted that contact has already been made with the universities (particularly Leeds), and some recruiting of young men, although not nearly enough, has been so effected with great advantage to the industry. Co-operation with the Board of Education has meant a considerable extension of such training as can be given by evening teaching in technical schools to the coming non-commissioned ranks, both for gas-manufacture and for supply.

Discussion and reports on technical and other matters are very full and frequent, partly because the various gas companies and municipal gas departments are not in direct competition with one another and can pool information more freely on that account. This is more particularly the province of the central Institution of Gas Engineers (and the branch associations), which in the past have rather tended to regard gas-engineering and gas-manufacture as the same thing, but are, slowly it is true, broadening their views and basis of membership so as to recognize the essential unity of the whole gas-engineering profession. The Society of British Gas Industries has served as a meeting-ground for the many industries concerned with the manufacture of gas plants and appliances for both domestic and industrial use ; the British Commercial Gas Association has made itself responsible for publicity work, while the National Gas Council and, more recently, the Gas Federation, have effected co-ordination on matters of common interest, particularly on the financial, legal and political sides. Co-operative research work has been so far mainly the concern of the Institution of Gas Engineers through its Executive Research Committee and the Joint Research Committee of the Institution and the University of Leeds-a pioneering effort which has met with much success over a long term of years. There has, however, been also instituted a considerable research organization in the larger gas companies (particularly in London), contracting firms and appliance manufacturers.

The report is appreciative up to a point of all that the gas industry has done in organizing itself, but calls for a greater effort, and particularly a form of organization which shall include a new central authority within the industry for the coordination of its many activities. It would aim at giving full opportunities for the personnel of the industry to exercise its talents for the more general good and for the recruiting and training of first-class men. It would seek to effect an improvement, which is indeed needed in most of the industries of Great Britain, by not only securing an adequate supply of research workers, but also ensuring that the results of their work are understood and utilized by the executive management. It would aid schemes of development and amalgamation which it approved, and would claim a right to prohibit what it believed to be ill-advised.

Such extensive powers would plainly only be given after full consideration of their implications, and under such conditions as would not allow vested interests or bureaucratic self-confidence to impede travel along new paths. The long view is essential in such matters, and the future possibilities in the treatment of coal by the gas and cognate industries were perhaps never so alluring as at the present time. The use of high temperatures and pressures in combination for the gasification of coal is bringing into prominence new reactions for the controlled transformation of 'fixed carbon' into methane and other hydrocarbons, and the various technical potentialities of the gasification process, chemical and thermal, are awaiting more complete investigation. Moreover, perhaps the most striking feature of recent progress in the technical world has been the new chemical engineering which is emerging from a vastly increased knowledge of materials of construction, particularly in the metallurgical field, and this is going to facilitate enormously not only the laboratory investigation of determining conditions but also the translation of the results into large-scale processes. The gas industry has splendid opportunities, but only a well-founded and well-manned vessel can hope to sail these uncharted seas. 